\title{
ON-LINE RADIOCARBON MEASUREMENTS OF SMALL SAMPLES USING ELEMENTAL ANALYZER AND MICADAS GAS ION SOURCE
}

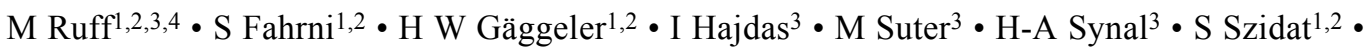 \\ L Wacker ${ }^{3}$
}

\begin{abstract}
An on-line measurement system was installed at the MICADAS in Zurich, using an elemental analyzer (EA) as a combustion unit to enable direct radiocarbon measurement of samples containing carbon in the range of 5-100 $\mu \mathrm{g}$ possible with minimum effort. The samples are combusted in small capsules and the gaseous combustion products are separated by the EA. The carbon dioxide leaving the EA in a high helium flow is concentrated on a small external trap containing X13 zeolite adsorber material. This new concept, avoiding a cryogenic trapping for the enrichment step, allows the construction of a very compact system able to work even with the smallest samples. Concentrated on the external trap, the carbon dioxide is flushed into the gas-tight syringe of our gas inlet system using a low helium stream. The gas mixture is measured with the MICADAS gas ion source. Several different sample capsules were analyzed to minimize the major blank contribution coming from the sample vessel. The best results were achieved with $25-\mu \mathrm{L}$ tin capsules, which contained only $0.34 \pm 0.13 \mu \mathrm{g}$ carbon at $65 \mathrm{pMC}$. This work describes the development of the on-line system and the protocol for measurement runs. Results are presented for on-line measurements of reference materials and a comparison is performed with typical dating samples measured previously as graphite targets. Finally, relevance and limitations of on-line measurements are discussed.
\end{abstract}

\section{INTRODUCTION}

The gas ion source of the small 200kV MICADAS (MIni CArbon DAting System) accelerator system at ETH Zurich (Ruff et al. 2007; Synal et al. 2007) has become a routinely used sample introduction system for radiocarbon measurements of small samples ( $<100 \mu \mathrm{g}$ carbon). Most of the $>500$ samples measured within the last 2 yr have been handled with our ampoule cracker system (Ruff et al. 2010). This method is very useful for small samples containing carbon in the range of $1-40 \mu \mathrm{g}$, which have to be treated in a special manner during sample preparation. An example is the separation of organic and elemental carbon from carbonaceous aerosols at different combustion temperatures (Szidat et al. 2004). However, this method requires a relatively large effort to combust the samples and to transfer them to glass tubes for the measurement. Hence, we began to look for a more economical way to measure small samples in routine operation.

On-line sample combustion with direct accelerator mass spectrometry (AMS) measurement provides an efficient and cost-effective solution. The first systems where an elemental analyzer (EA) as a combustion unit was coupled on-line with the ion source of an accelerator mass spectrometer were described by the Oxford and Erlangen AMS groups (Bronk Ramsey et al. 2004; Uhl et al. 2004). Such systems can be completely automated, which in our opinion is the final goal of on-line measurements. Due to the small sample masses, precision is limited at the moment to approximately $1 \%$ (Ruff et al. 2007). However, there is an increasing potential for samples that do not have to be measured very precisely, but in large numbers (e.g. in the field of biomedical or environmental research). For this purpose, a completely automated on-line system for measuring small samples with a precision in the range of $1-5 \%$ will be the ideal facility. Such a system can also be coupled with other analytical instruments like a gas chromatograph (Bronk Ramsey and Hedges 1995) or even an HPLC system (Skipper et al. 2004). Additionally, the handling of small samples, very sensitive to ultra-small contamination, will be much easier compared to a cracker system (Ruff et al. 2007) or even a graphitization system.

\footnotetext{
${ }^{1}$ Laboratory for Radio- and Environmental Chemistry, University of Bern, Switzerland.

${ }^{2}$ Paul Scherrer Institute, Villigen, Switzerland.

${ }^{3}$ Laboratory for Ion Beam Physics, ETH Zurich, Switzerland.

${ }^{4}$ Corresponding author. Email: matthias.ruff@eawag.ch.
} 
This work presents a new approach for coupling of an elemental analyzer via a gas interface to the gas ion source of an AMS facility. The system is developed for small samples containing carbon in the range of 5-100 $\mu \mathrm{g}$. As an EA works under high carrier gas flow in order to support the combustion and perform the gas separation in a suitable time, the low volume of carbon dioxide being produced by the small samples gets highly diluted. Both existing systems in Oxford and Erlangen work with cryogenic traps for concentrating the carbon dioxide of the sample (Bronk Ramsey et al. 2004; Uhl et al. 2004). In our work, we use a molecular sieve trap, which allows us to work without using any liquid nitrogen. This approach enables easy automation of the system. We present a complete setup, material tests, and validation data with different substances, to demonstrate the reliability of our measurements and discuss the limitations of on-line measurements using an EA system.

\section{INSTRUMENTAL SETUP AND EXPERIMENTS}

\section{System Overview}

The on-line ${ }^{14} \mathrm{C}$ measurement system has 4 main components (Figure 1):

1. Elemental analyzer for sample combustion;

2. External trap for enrichment of the carbon dioxide;

3. Gas inlet system for continuous and constant $\mathrm{CO}_{2}$ introduction into the AMS;

4. MICADAS AMS facility with its gas ion source.

(1) and (2) are integrated in an existing gas inlet system (3) based on an ampoule cracker built for measuring small gaseous samples supplied in glass ampoules (Ruff et al. 2007). Briefly, the heart of the existing gas interface is a 1.3 -mL gas-tight syringe (Hamilton, Reno, USA) serving as a sample reservoir, which can be adjusted to the carbon content of the sample. The plunger is moved by a stepping motor, pressing the mixture of sample $\mathrm{CO}_{2}(5 \%)$ in helium into the ion source with a constant flow of $36 \mu \mathrm{L} / \mathrm{min}$ (STP). By increasing the $\mathrm{CO}_{2}$ concentration up to $12 \%$, measurements of samples up to $100 \mu \mathrm{g}$ are possible. However, the $\mathrm{CO}_{2}$ level plotted against efficiency shows a maximum at a ratio of 5\%. Higher ratios lead to lower ion production efficiencies in the ion source, which can only be accepted for large samples where too long measurement times start playing an important role.

The 2 similar measurement parts (cracker and on-line system) have been combined in the inlet system by introducing a multiposition valve (VICI, Houston, USA) connecting the gas-tight syringe with either the on-line features or the ampoule cracker. In the following, the on-line part will be discussed in detail.

\section{Elemental Analyzer}

We use a Vario Micro elemental analyzer (ELEMENTAR, Hanau, Germany), which is designed for samples in the low milligram range. The inner volume of the apparatus could be further reduced by using smaller combustion and reduction tubes (14 mm ID instead of $20 \mathrm{~mm}$ ). The EA is operated with a reduced permanent flow of $80 \mathrm{~mL} / \mathrm{min}$ helium as carrier gas (by default $200 \mathrm{~mL} / \mathrm{min} \mathrm{He}$ flow). The temperature of the combustion unit is set to $950{ }^{\circ} \mathrm{C}$ and the sample is combusted in a helium atmosphere temporarily enriched with oxygen. The combustion gas containing carbon monoxide, carbon dioxide, water, nitrogen oxides, and possibly sulfur oxides are transmitted through a copper oxide bed inside the combustion tube to support complete oxidation of the gaseous products. The oxidation of carbon monoxide to carbon dioxide is completed here. Sulfur oxides are chemically removed by a reaction with lead chromate in a second bed in the combustion tube. After the transfer to the reduction unit operated at $550{ }^{\circ} \mathrm{C}$, pure copper reacts with excessive oxygen and the nitrogen oxides to copper oxide and pure nitrogen, respectively. 


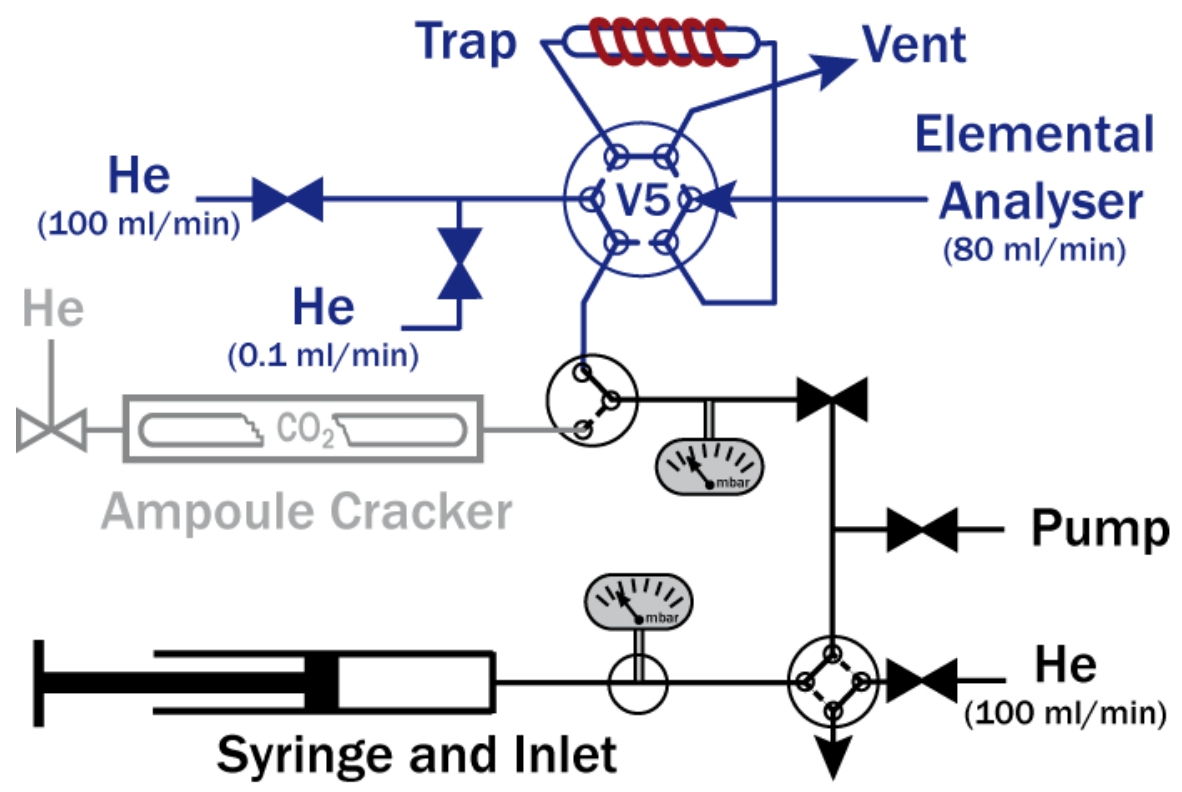

\begin{abstract}
AMS
Figure 1 Scheme of the EA-AMS coupling interface including the EA, the on-line interface with its external trap (blue), the gas inlet system with pump, pressure sensors and syringe (black), and finally, the AMS. The on-line system is connected to the existing ampoule cracker (gray) (Ruff et al. 2007).
\end{abstract}

The remaining gases $\left(\mathrm{N}_{2}, \mathrm{CO}_{2}, \mathrm{H}_{2} \mathrm{O}\right)$ are separated chromatographically in a U-shaped, tempered column. While nitrogen passes through the column without being retained, carbon dioxide and water are trapped at temperatures lower than $50{ }^{\circ} \mathrm{C}$. The carbon dioxide is remobilized by heating the trap to $80^{\circ} \mathrm{C}$, while water stays on the trap and is flushed out at higher temperatures. The separated gases are quantified in a thermal conductivity detector and are usually released into the atmosphere, whereas in our case the gases are flushed into the gas interface. Thus, the elemental analysis results in 3 well-separated peaks of nitrogen, carbon dioxide, and water in an $80 \mathrm{~mL} / \mathrm{min}$ helium gas flow after an analysis time of $13 \mathrm{~min}$.

\title{
Gas Interface with External Trap
}

Figure 1 shows a schematic drawing of the actual system. Central for the on-line measurement is the external trap to enrich the carbon dioxide leaving the elemental analyzer in a high helium stream. The 6-port, 2-position valve (V5 in the scheme) can be switched between the external trap and the atmosphere. Note that the combustion gases have been separated by the EA; thus, the $\mathrm{CO}_{2}$ peak contains pure $\mathrm{CO}_{2}$ in helium. The valve is switched so that only the $\mathrm{CO}_{2}$ peak is adsorbed on the external trap, while the nitrogen peak before and the water peak thereafter are directly released into the atmosphere. To implement the external trap, we compared the usual cryogenic trapping technique (stainless steel capillary with 0.5 and $1 \mathrm{~mm}$ ID and 25/50/100 cm length) with a new technique using a solid adsorption material. Four different substances (all from Sigma Aldrich Corporation, St. Louis, USA) have been tested for their adsorption and desorption properties:

1. Silica gel;

2. Carbosphere, a spherical carbon molecular sieve;

3. 5A, a cubic zeolite molecular sieve (alkali aluminosilicate);

4. X13, an X-structured zeolite molecular sieve (sodium aluminosilicate). 
To optimize the adsorption using the molecular sieve method, different geometries of the external trap were tested in order to minimize the trap volume and the dead volume, and to optimize the desorption process. We started using a trap with $4.5 \mathrm{~mm}$ ID and $50 \mathrm{~mm}$ length. The trap was O-ring sealed for testing silica gel and carbosphere as we expected to heat the trap no higher than $200{ }^{\circ} \mathrm{C}$. Some $480 \mathrm{mg}$ silica gel and $414 \mathrm{mg}$ carbosphere were used to fill the traps. The trap holding the molecular sieve was constructed completely of metal, since for maximum desorption of the fixed $\mathrm{CO}_{2}$ the trap has to be heated to $500^{\circ} \mathrm{C}$. We continuously decreased the volume of the trap used for the zeolite adsorber and ended up with a final ID of $3.2 \mathrm{~mm}$ and a length of $14 \mathrm{~mm}$. A heating coil (Watlow, St. Louis, USA) is wrapped around the trap heating it with a rating of $200 \mathrm{~W}$. The final external trap can be heated up from room temperature to $500^{\circ} \mathrm{C}$ in about $40 \mathrm{~s}$. A K-type temperature sensor (Watlow, St. Louis, USA) fixed on the surface of the trap is connected to a temperature controller (Omron, Kyoto, Japan) for regulation.

When the heating process is started, the trap is continuously back-flushed with just enough helium flow $(\sim 100 \mu \mathrm{L} / \mathrm{min})$ to transport the $\mathrm{CO}_{2}$ directly into the syringe of the gas interface without allowing back-diffusion from the trap into the capillary system (Figure 1). Most of the $\mathrm{CO}_{2}$ is rapidly desorbed between 250 and $500{ }^{\circ} \mathrm{C}$. During this desorption period of about $40 \mathrm{~s}$, the whole $1.3 \mathrm{~mL}$ volume of the syringe is used and the pressure rises to about 200 mbar. To keep the ratio of $\mathrm{CO}_{2}$ and $\mathrm{He}$ constant $(5 \%)$, the volume of the syringe has now to be adjusted corresponding to the size of the sample by moving the plunger forward. While a sample containing $40 \mu \mathrm{g}$ carbon $\left(80 \mu \mathrm{L} \mathrm{CO}_{2}\right.$ at RT) uses the whole volume of the syringe, the volume has to be reduced to about $0.16 \mathrm{~mL}$ for a sample containing $5 \mu \mathrm{g}$ carbon. The syringe is filled up to a final pressure of $1200 \mathrm{mbar}$ with He flushed through the trap. A recovery test was performed with the trap actually used by simply heating the trap up to $500{ }^{\circ} \mathrm{C}$ without using the low helium flow of $100 \mu \mathrm{L} / \mathrm{min}$ for flushing. The pressure of the carbon dioxide in the previously calibrated system was measured and recalculated to the $\mathrm{CO}_{2}$ amount with which the trap was loaded. Different carbon masses from 20-100 $\mu$ g were tested.

The external trap is sensitive to cross-contamination processes, especially for small samples. For this reason, we use an extensive procedure for cleaning the trap between 2 samples. The temperature is kept at $500{ }^{\circ} \mathrm{C}$ during the whole process:

- Back-flushing with a pure helium flow of about $10 \mathrm{~mL} / \mathrm{min}$ for $2 \mathrm{~min}$;

- Pumping and back-filling several times with helium;

- Flushing the trap with a He flow from the elemental analyzer $(80 \mathrm{~mL} / \mathrm{min}$ in the direction the trap is loaded) by switching valve V5 for $1 \mathrm{~min}$;

- Again, pumping and back-filling for several times with $10 \mathrm{~mL} / \mathrm{min}$;

- Stopping the He flow and evacuating the trap for $1 \mathrm{~min}$;

- Cooling down the trap under vacuum using an external fan.

The cleaning procedure takes about $6 \mathrm{~min}$. Then, the trap is kept at room temperature under vacuum conditions until the loading process starts again.

\section{Sample Capsules}

Proper operation of the EA auto-sampler requires that sample materials be wrapped into tin capsules for the measurement, to ensure that they fall cleanly into the combustion tube. During the combustion process, the tin is oxidized in an exothermic reaction, raising the effective combustion temperature to $1250-1350^{\circ} \mathrm{C}$. However, the tin capsules also cause a carbon blank in the low $\mu \mathrm{g}$ range, as they are specified for samples in the $\mathrm{mg}$ range, where $\mu \mathrm{g}$ contamination levels are insignificant. 
Three different vessels all made of tin were delivered by ELEMENTAR. Two of them are cupshaped capsules with $25 \mu \mathrm{L}(35 \mathrm{mg})$ and bigger ones with $50 \mu \mathrm{L}(88 \mathrm{mg})$ volume. The third vessel is boat-formed and consists of very thin tin foil with a weight of only $35 \mathrm{mg}$. Three other tin and silver capsules have been compared and are presented here (Table 1). Note that all results published in Table 1 are averaged values over 2 capsules as the carbon contamination of the vessels is close to the detection limit of our elemental analyzer. We also ordered pure metal foils (tin, silver, and aluminium) for preparing our own capsules, and tested a cleaning procedure for reducing surface contamination: capsules and metal foils were washed in acetone and water and dried for $30 \mathrm{~min}$ at $130^{\circ} \mathrm{C}$.

Table 1 Carbon contents for different sample capsules obtained as average values of 2 vessels. All these capsules have been measured with ("cleaned") and without ("new") cleaning procedure in acetone/water. The numbers marked with asterisks were measured at the PSI Laboratory for Atmospheric Chemistry. More information about the data is given in the text.

\begin{tabular}{|c|c|c|c|c|c|}
\hline \multirow[t]{2}{*}{ Material } & \multirow[t]{2}{*}{ Type } & \multirow{2}{*}{$\begin{array}{l}\text { Weight } \\
(\mu \mathrm{g})\end{array}$} & \multirow{2}{*}{$\begin{array}{l}\text { Dimensions } \mathrm{H} \times \mathrm{W} \times \mathrm{D} \\
(\mathrm{mm})\end{array}$} & \multicolumn{2}{|c|}{$\mathrm{C}$ contamination $(\mu \mathrm{g} \mathrm{C})$} \\
\hline & & & & New & Cleaned \\
\hline \multicolumn{6}{|c|}{ ELEMENTAR standard material } \\
\hline & boat & 35 & $4 \times 4 \times 11$ & 1.1 & 0.5 \\
\hline \multirow[t]{2}{*}{ Tin } & capsule $25 \mu \mathrm{L}$ & 35 & $2.9 \times 6$ & 0.3 & 0.4 \\
\hline & capsule $50 \mu \mathrm{L}$ & 88 & $3.5 \times 9$ & 0.6 & 0.5 \\
\hline \multicolumn{6}{|c|}{ Special capsules } \\
\hline $\operatorname{Tin}^{\mathrm{a}}$ & capsules & 54 & $3.4 \times 4$ & $0.3^{*}$ & 0.3 \\
\hline $\operatorname{Tin}^{\mathrm{b}}$ & capsules & 10 & $3.5 \times 5$ & $0.4^{*}$ & 0.4 \\
\hline Silver $^{\mathrm{a}}$ & capsules & 13 & $3.3 \times 5$ & $0.8^{*}$ & 0.8 \\
\hline \multicolumn{6}{|c|}{ Different metal foils ${ }^{\mathrm{c}}$} \\
\hline Tin & 0.999 & 78.3 & $21 \times 21$ & 4.9 & 2.7 \\
\hline Aluminium & 0.999995 & 45.1 & $21 \times 21$ & 5.6 & 3.7 \\
\hline Silver (1) & 0.99998 & 86.2 & $18 \times 18$ & 3.9 & 2.7 \\
\hline Silver (2) & 0.999 & 225.5 & $21 \times 21$ & - & 3.5 \\
\hline
\end{tabular}

${ }^{a}$ Säntis Analytical AG, Teufen, Switzerland.

${ }^{\mathrm{b}}$ Costech Analytical Technologies, Valencia, California, USA.

cAll: Alfa Aesar GmbH, Karlsruhe, Germany.

\section{Radiocarbon Measurement}

Measurement was done at the 200kV MICADAS accelerator, the smallest AMS facility located in Zurich. More details on measurement parameters of the source are given in Ruff et al. (2007), with further information about the AMS machine in Synal et al. (2007).

As measurement time on an AMS machine is expensive and limited, the measurement itself should be the most time-consuming step for the on-line system. For this reason, most steps of the sample combustion and loading procedure should be done in parallel to the AMS measurement. In Figure 2, a typical time schedule of a measurement is given. The minimum time of 17 min needed for the whole procedure is defined by the sum of the time windows, which are fixed. The loading process of the trap is defined by the $\mathrm{CO}_{2}$ desorption peak leaving the EA. This time is available for cleaning the syringe with pure helium, as the syringe is not connected to the external trap during that period (see also Figure 1). The heating and flushing of the trap requires about 2 min until the syringe is loaded and the desired ratio of $5 \% \mathrm{CO}_{2}$ in $\mathrm{He}$ is reached. The measurement time at the MICADAS 
has to be at least as long as the time required for cleaning the trap (6 min) and cooling it down to room temperature with a fan $(4 \mathrm{~min})$. As the flow into the ion source is $1 \mu \mathrm{g} \mathrm{C} / \mathrm{min}$, these $10 \mathrm{~min}$ are sufficient to consume a sample containing $10 \mu \mathrm{g} \mathrm{C}$. Thus, the system is best suited for continuous measurements of sample sizes $>10 \mu \mathrm{g}$ carbon. As the nitrogen peak is not used, combustion in the EA can be started when the measurement of the preceding sample is still running. Six minutes is sufficient time for pre-sputtering (clean-up) the Ti targets of the ion source (Ruff et al. 2007) (2-5 min needed due to our experience from previous gas measurements: Ruff et al. 2010).

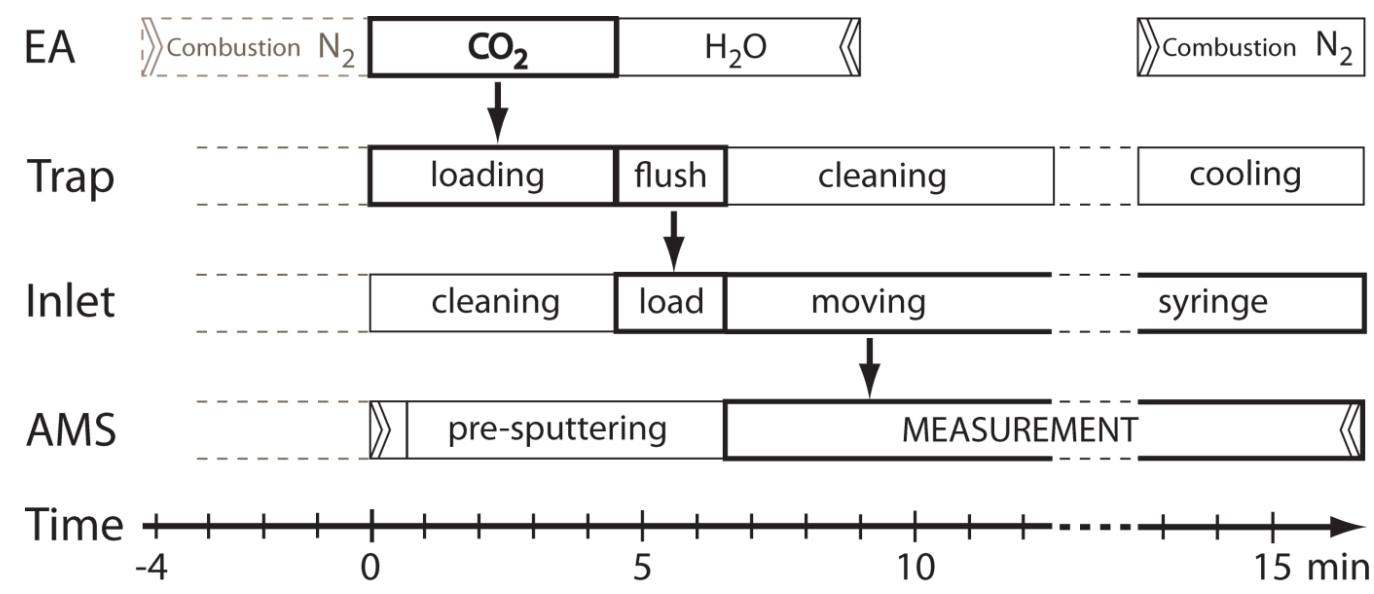

Figure 2 Time schedule of the on-line measurement for each of the 4 major components of the gas facility. The bold frames show the path of the sample $\mathrm{CO}_{2}$ through the system. A detailed description of the scheme is given in the text.

For a validation of the on-line method, IAEA reference material C5 and C7 have been measured in different measurement series. The material was weighed on an ultra-sensitive balance (resolution: 1 $\mu \mathrm{g}$ ) and filled into cylindrical tin capsules (ELEMENTAR) of $35 \mathrm{mg}$. Additionally, we repeated measurements of samples that had already been measured as graphite with the 6MV EN tandem AMS system. We used solid Ox-II standard material for the standard normalization and coal for blank determinations, measured with the on-line system under same conditions, i.e. in same capsules and in the same range of carbon content.

\section{RESULTS AND DISCUSSION}

\section{External Trap}

The results obtained from the cryogenic adsorption technique were not encouraging, because in all different capillaries unacceptable breakthroughs were observed for samples of about $100 \mu \mathrm{g}$ carbon. The experiments with the 0.5 -mm-ID capillaries failed, because the traps became blocked with frozen $\mathrm{CO}_{2}$ and the tests with the 2 short 1-mm-ID capillaries resulted in breakthroughs up to $10 \%$. Even with the longest tested capillary of $100 \mathrm{~cm}$, which was shaped into multiple bends, we detected a breakthrough of about $4 \%$ using a quadrupole gas mass spectrometer. This reduced recovery may be due to $\mathrm{CO}_{2}$ crystals being knocked from the capillary wall by the high helium flow (B Kromer, personal communication). Because of the large inner volume of a 100-cm capillary, the recovery for flushing the $\mathrm{CO}_{2}$ into the syringe will decrease continuously when working with small samples. Thus, we decided the cryogenic trapping technique was not the method of choice. 
For the trapping technique using adsorber materials, 4 different substances were tested as described above. For silica gel as well as carbosphere, we encountered continuous breakthroughs right from the beginning of the loading process, detected qualitatively in the outgoing gas stream with a gas mass spectrometer. The 50-mm-long trap seems to contain too little adsorber material, but using much larger traps would unnecessarily increase the dead volume of the system.

First tests with a welded column containing $450 \mathrm{mg}$ of the $\mathrm{X} 13$ zeolite adsorber were encouraging, as we did not detect any breakthrough, but we could only desorb the $\mathrm{CO}_{2}$ from the trap with a high helium flow. Consequently, we constructed a series of smaller traps containing 200 and $80 \mathrm{mg}$ of zeolite material. For both the 5A and the similar X13 zeolite, breakthroughs were not observed even with the smallest version. For easier handling and in order to improve the $\mathrm{CO}_{2}$ adsorption, we changed the inner diameter of the small trap to $3.2 \mathrm{~mm}$ instead of $4.5 \mathrm{~mm}$ and ended up with a trap containing just $61 \mathrm{mg}$ of X13 material. We took special care to construct a very compact trap in order to avoid unnecessary dead volumes and determined the inner volume of the trap to be about $115 \mu \mathrm{L}$. The trap is connected to valve V5 (Figure 1) of the gas interface via two 1/16" tubes, which were kept as short as possible to minimize the volume of the gas capillaries before and especially behind the trap. The whole trap including the connection screws can be heated with the heating coil to temperatures more than $500{ }^{\circ} \mathrm{C}$.

The recovery was determined by heating the loaded and subsequently evacuated trap to $500{ }^{\circ} \mathrm{C}$ and measuring the pressure in a defined volume. The achieved recovery of our trap is $95-100 \%$ for sample masses up to $80 \mu \mathrm{g}$ carbon. With higher sample masses of 80-100 $\mu \mathrm{g}$ carbon, the recovery decreases slightly to $90-95 \%$. We assume that this decrease is a hint for the onset of breakthrough of the external trap, because size of the trap and amount of zeolite adsorber are calculated to be close to the limit. Nevertheless, the capacity of the trap is sufficient when working with a maximum of $100 \mu \mathrm{g}$ carbon, and the good recovery and low sample-to-sample memory of the trap validate the decision to keep the volume as small as possible. The results of the recovery experiment are consistent with the data presented by Bauer et al. (1992). They used an X13 zeolite trap to remove submilligram amounts of $\mathrm{CO}_{2}$ from a high flow nitrogen and oxygen stream and reported a $100 \%$ loading and releasing recovery for their experiments. However, these authors used much larger amounts of $\mathrm{X} 13$ zeolite material for their adsorber column. Moreover, they released the trapped $\mathrm{CO}_{2}$ by just heating the trap to $425^{\circ} \mathrm{C}$ for several minutes. In our case, we have improved the release process for small samples, which starts at temperatures of about $250{ }^{\circ} \mathrm{C}$, by using a higher temperature and flushing the trap with a flow of $100 \mu \mathrm{L} / \mathrm{min}$ of helium as described above.

The cleaning procedure described above proved to be very important. Blank contributions from the EA are negligible, but the external trap is sensitive to cross-contamination, because the carbon dioxide is concentrated here. By measuring standard and blank samples in series, we calculated a crosscontamination caused by the trap of up to $2 \%$ at the beginning of our experiments. However, by introducing the described cleaning procedure, the cross-contamination was reduced to $<0.4 \%$.

\section{EA Capsules}

While we found the lowest carbon contamination in the range of $0.2-0.4 \mu \mathrm{g}$ of carbon (Table 1) in the small capsules from ELEMENTAR, the bigger capsules were contaminated with amounts of $\sim 0.6 \mu \mathrm{g}$ of carbon. The blank for the boats was even larger than $1 \mu \mathrm{g}$ of carbon. After cleaning the tin vessels, however, the contaminations could be reduced for the bigger capsules and the boats to $0.5 \mu \mathrm{g}$ carbon. The contamination of the small capsules could not be further reduced by cleaning, and after the procedure they actually gave slightly higher values than originally measured. Note that each value for the capsule contamination given in Table 1 is averaged over 2 measured capsules, as 
the low carbon contents are close to the limit of quantification of the EA's thermal conductivity detector.

It seems that the contamination correlates with the surface area of the vessel and the mass. To determine whether the contamination is on the surface or in the bulk of the material, we analyzed the tin foil of a boat-shaped vessel with the ERDA (elastic recoil detection analysis) technique in our laboratory (Kottler et al. 2006). Because the contamination is very low, we were not able to quantify the absolute concentration profile of the foil, but we observed qualitatively that the concentration of carbon got lower the deeper the beam entered the material. This confirms the results shown in Table 1 and explains why the contamination could partially be reduced by a cleaning procedure.

Most of the capsules were tested in cooperation with the PSI Laboratory for Atmospheric Chemistry, who also did analyses to compare our data. Three additional types of their commonly used capsules are presented in Table 1. Some of these capsules were transferred to our laboratory but only analyzed after cleaning as we suspected a contamination caused by the transport. Two of the tested capsules, a tin and a silver capsule, are very low in mass (10 and $13 \mathrm{mg}$, respectively), but the contamination of 0.4 and $0.8 \mu \mathrm{g}$ carbon are nevertheless relatively high. The other cup (54 mg) is even heavier than the 25- $\mu$ L ELEMENTAR standard capsule but gave a similar result of only $0.3 \mu \mathrm{g}$ carbon contamination. The results we found for these capsules are in perfect agreement with the contamination amounts determined by the PSI group. A similar capsule contamination reported by the Oxford AMS group (Bronk Ramsey et al. 2004) was found to be in the range of 0.2-0.4 $\mu \mathrm{g}$ carbon for their tin capsules, too.

The pure metal foils we tested were all much more contaminated than we expected. Table 1 presents the values measured before and after the cleaning procedure for the tested tin, aluminium, and 2 silver foils. We found high blank values for the original foils, which were reduced to about $50 \%$ by cleaning the surface in acetone/water. However, these blank levels were still too high, so we did not attempt to produce our own capsules.

Consequently, the standard $25-\mu \mathrm{L}$ capsules from ELEMENTAR were found to be the most suitable sample vessels in our test series. They are big enough for the small amounts of sample material we are going to use, they do not need extra cleaning, and furthermore, they are inexpensive. However, these small capsules are not easy to handle because of their small diameter of only $2.9 \mathrm{~mm}$.

\section{Sample Correction}

Assuming that the contamination of the EA capsules is constant, a sample correction can be performed using the model of constant contamination:

$$
\begin{gathered}
m(C)_{\text {sample }} \times\left(\frac{{ }^{14} C}{{ }^{12} C}\right)_{\text {sample }}=m(C)_{\text {meas }} \times\left(\frac{{ }^{14} C}{{ }^{12} C}\right)_{\text {meas }}-m(C)_{\text {cap }} \times\left(\frac{{ }^{14} C}{{ }^{12} C}\right)_{\text {cap }} \\
m(C)_{\text {sample }}=m(C)_{\text {meas }}=m(C)_{\text {cap }}
\end{gathered}
$$

According to Equations 1 and 2, the product of sample mass and ${ }^{14} \mathrm{C}$ content of the sample is equal to the product of the mass and the ${ }^{14} \mathrm{C}$ content of the capsule (cap) subtracted from the measured product of mass and ${ }^{14} \mathrm{C}$ content (meas), while the real mass of the sample is the carbon mass of the capsule subtracted from the measured value. To calculate the ${ }^{14} \mathrm{C}$ content of the sample, carbon content and $\mathrm{pMC}$ value of the capsule have to be determined. 
The variation in contamination of the single capsule was investigated in 2 experiments. However, as the carbon content of 1 capsule is close to the limit of quantification, a measurement in the standard mode of our ELEMENTAR elemental analyzer was not possible. Therefore, we increased the amplified output of the detector signal (causing also a higher scatter of the data). A carbon content of $0.39 \pm 0.05 \mu \mathrm{g}$ per capsule with a scatter of $0.14 \mu \mathrm{g}(n=9)$ was determined. To confirm this value, we repeated the single-capsule measurements on a different batch of tin capsules at the PSI Laboratory for Atmospheric Chemistry using their more sensitive elemental analyzer coupled to a ${ }^{13} \mathrm{C}$ isotopic ratio mass spectrometer (Thermo Fisher, San Jose). There, a value of $0.29 \pm 0.03 \mu \mathrm{g}$ carbon with a scatter of $0.09 \mu \mathrm{g}(n=8)$ was achieved. The 2 values agree within their 2- $\sigma$ uncertainties. A mean of $0.34 \pm 0.03 \mu \mathrm{g}$ of all measurements with a scatter of $0.13 \mu \mathrm{g}(n=17)$ was calculated. However, the difference of the 2 experiments could also be an indication for slightly varying contaminations in different batches.

To calculate the pMC level, 5 capsules were combusted together twice, collecting $3.3 \mu \mathrm{g}$ carbon as carbon dioxide on the zeolite trap of the inlet system. An average pMC value of $65 \pm 6$ was measured with the gas ion source of the MICADAS. To verify these data, all our 39 blank data measured in different data sets were plotted against the amount of carbon determined with the elemental analyzer (Figure 3, closed and open dots). The blue continuous line represents the calculated capsule contamination according to the model of constant contamination using the previously determined data for the carbon contamination $(0.34 \pm 0.13 \mu \mathrm{g} \mathrm{C})$ and the measured average ${ }^{14} \mathrm{C}$ level of $65 \mathrm{pMC}$. The measured data for the blank samples larger than $8 \mu \mathrm{g}$ total carbon were in good agreement with the calculated curve with its uncertainty derived from the variation of the carbon mass. It can therefore be concluded that the ${ }^{14} \mathrm{C}$ level of the contamination varies only insignificantly between different capsules. For the few samples smaller than $8 \mu \mathrm{g}$ carbon, the measured values poorly fit into our model, suggesting that the constant contamination might be higher. This is in agreement with previously acquired data, where for samples smaller than $8 \mu \mathrm{g} \mathrm{C}$ significantly lower currents were achieved $(<2 \mu \mathrm{A} \mathrm{C}$ current), resulting in a much higher influence of the contamination coming from the titanium target (Ruff et al. 2010). Mainly for this reason, we suggest a lower limit for our on-line measurement technique to $10 \mu \mathrm{g} \mathrm{C}$. However, Figure 3 again indicates that different batches of capsules (first data set with closed dots against second data set with open dots) can lead to different results. To calculate with an uncertainty of $\sim 40 \%$ for the capsule contamination seems appropriate.

The capsule contamination of $0.34 \pm 0.13 \mu \mathrm{g} \mathrm{C}$ with its ${ }^{14} \mathrm{C}$ content of $65 \mathrm{pMC}$ biases the result of a measurement as follows: while a $8-\mu \mathrm{g}$ sample with $1 \mathrm{pMC}$ (blank sample) is increased by the capsule to about 2.5-4 pMC, a 20- $\mu \mathrm{g}$ sample is still affected to $1.5-2.5 \mathrm{pMC}$. Hence, the contribution of the capsule has to be subtracted from each sample according to the previously mentioned model of constant contamination. Performing the correction, the mean of blank samples in the range of $20 \pm$ $10 \mu \mathrm{g} \mathrm{C}$ is $1 \mathrm{pMC}(\sim 36,000 \mathrm{BP})$. This blank value is almost independent of size for samples $>10 \mu \mathrm{g}$ C. The value represents the limit of the on-line method and is comparable to the value of $0.8 \mathrm{pMC}$ ( $38,500 \mathrm{BP})$ reached for off-line measurements using the cracker system (Ruff et al. 2010).

\section{Radiocarbon Measurements}

Table 2 presents the results of the analyzed IAEA-C5 and -C7 standard material. The 12 values are measured in 6 different measurement series. Nine of the values are in good agreement with the nominal values within the $1-\sigma$ range, which corresponds to the given uncertainty. All measurement points agree within the 2- $\sigma$ range. Not all samples have been measured with the same current, which is reflected in different uncertainties for similar sample sizes. The calculated mean of means is for both standard materials not significantly different from the nominal value ( $t$ test, 95\%). 


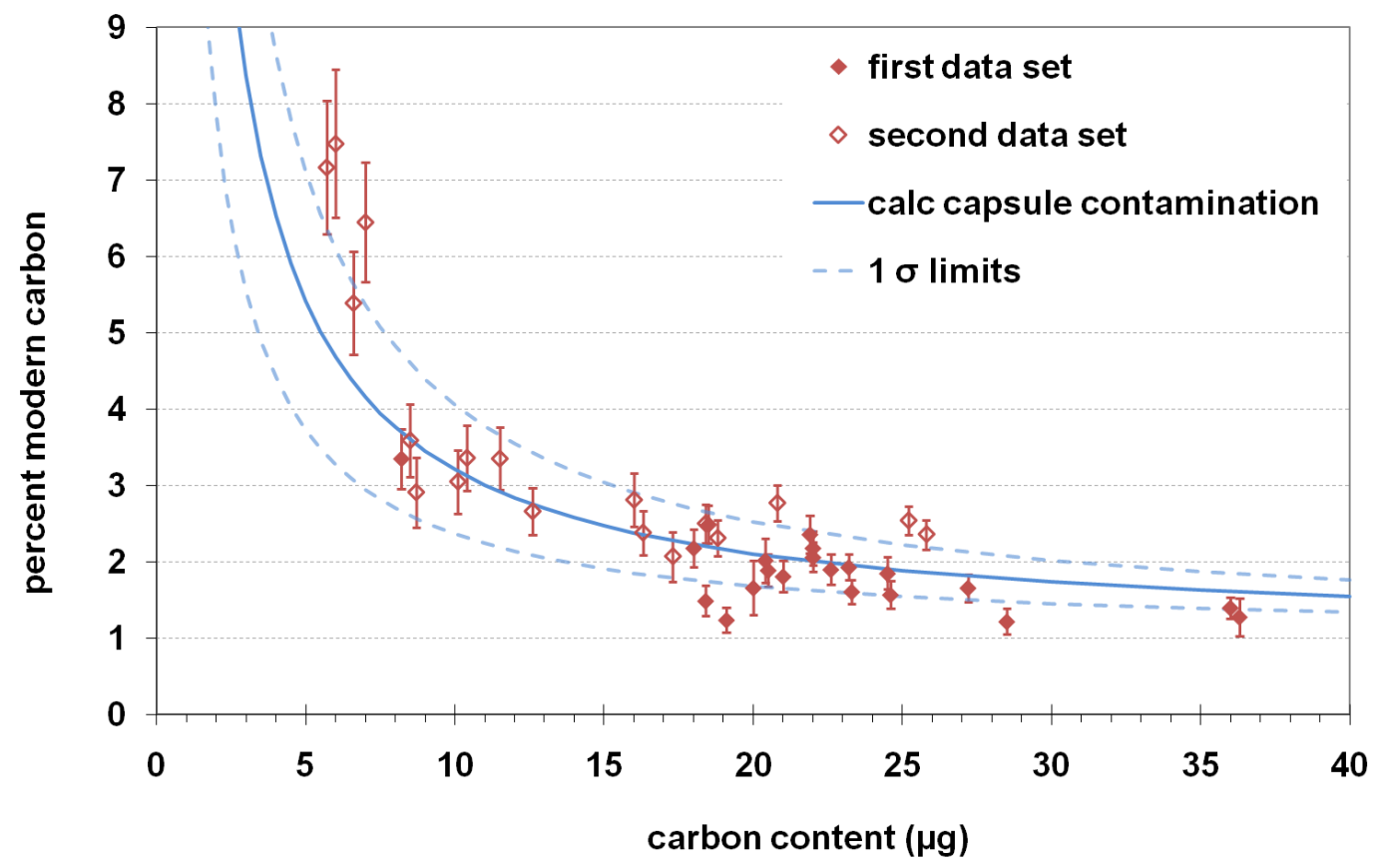

Figure 3 Measured pMC data of 39 blank samples (coal) plotted against total sample size determined with the elemental analyzer (no blank subtraction). Two independent measurement series are shown marked as closed and open dots. The blue line with its $1-\sigma$ uncertainty limits (dotted) is calculated assuming a constant contamination of $0.34 \pm 0.13 \mu \mathrm{g}$ with a pMC level of 65 .

Table 2 Results of the validation measurements using IAEA-C5 and -C7 reference materials with sample sizes in $\mu \mathrm{g}$ carbon per sample. The average value represents the mean of means with the recalculated uncertainty. The nominal values of the reference materials are given in the last line.

\begin{tabular}{lll|lll}
\hline \multicolumn{3}{c}{ IAEA-C5 } & & \multicolumn{3}{c}{ IAEA-C7 } \\
\hline$\mu \mathrm{g} \mathrm{C}$ & $\mathrm{pMC}$ & $\delta^{13} \mathrm{C}$ & $\mu \mathrm{g} \mathrm{C}$ & $\mathrm{pMC}$ & $\delta^{13} \mathrm{C}$ \\
\hline 26 & $22.52 \pm 0.61$ & -26.1 & 15 & $48.62 \pm 1.08$ & -16.3 \\
22 & $22.97 \pm 0.93$ & -41.2 & 20 & $48.48 \pm 1.00$ & -14.7 \\
25 & $22.48 \pm 0.63$ & -23.7 & 17 & $49.62 \pm 1.03$ & -15.6 \\
14 & $21.98 \pm 0.93$ & -29.1 & 36 & $48.94 \pm 0.84$ & -17.5 \\
23 & $23.06 \pm 0.61$ & -24 & 20 & $50.07 \pm 1.45$ & -14.7 \\
& & & 28 & $50.22 \pm 1.10$ & -15.7 \\
& & & 24 & $48.50 \pm 0.84$ & -13 \\
\hline Average & $22.64 \pm 0.31$ & -28.8 & & $49.07 \pm 0.38$ & -15.4 \\
Nominal & 23.05 & -25.5 & & 49.54 & -14.5 \\
\hline
\end{tabular}

We compared the measurements with results obtained at the 6MV EN tandem accelerator (Table 3). Exactly the same sample material was used performing the gaseous on-line measurements. The data agree well with the solid measurements done with a sample size of $2 \mathrm{mg}$ graphite instead of the 10 $27 \mu \mathrm{g}$ carbon used for the gaseous measurements. Most data points agree within the 1- $\sigma$ uncertainty range. 
Table 3 Validation data with different materials that have been measured as gaseous samples with the on-line system. The values are compared to the measurements with the 6MV EN tandem accelerator using $\sim 2 \mathrm{mg}$ graphite. The value of the reduced $\chi^{2}$ test over the 7 compared results is given in the last row.

\begin{tabular}{llllrll}
\hline Material & $\begin{array}{l}\text { Weight } \\
(\mu \mathrm{g} \mathrm{C})\end{array}$ & $\begin{array}{l}{ }^{14} \mathrm{C} \\
\text { counts }\end{array}$ & $\begin{array}{l}{ }^{12} \mathrm{C}^{+} \\
{ }^{14} \mathrm{C} \text { age gas } \\
\text { MICADAS }\end{array}$ & $\begin{array}{l}{ }^{14} \mathrm{C} \text { age solid } \\
\text { TANDEM }\end{array}$ & Conformity \\
\hline Bone & 22 & 2314 & 1.0 & $9208 \pm 240$ & $9205 \pm 75$ & $1 \sigma$ \\
Bone & 27 & 3423 & 1.1 & $8451 \pm 205$ & $8565 \pm 90$ & $1 \sigma$ \\
Charcoal & 18 & 3819 & 0.9 & $501 \pm 152$ & $715 \pm 50$ & $2 \sigma$ \\
Charcoal & 20 & 5051 & 1.0 & $876 \pm 135$ & $1105 \pm 50$ & $2 \sigma$ \\
Textile & 11 & 2368 & 1.0 & $1777 \pm 181$ & $1525 \pm 45$ & $2 \sigma$ \\
Textile & 23 & 6605 & 1.1 & $520 \pm 119$ & $435 \pm 40$ & $1 \sigma$ \\
Tooth & 21 & 4682 & 1.0 & $2095 \pm 146$ & $2070 \pm 55$ & $1 \sigma$ \\
\hline Reduced $\chi^{2}$ & $0.99(n=7)$ & & & & \\
\hline
\end{tabular}

\section{CONCLUSIONS}

The on-line measurement of samples containing 5-100 $\mu \mathrm{g}$ carbon, using an EA for combustion, has been established. We integrated the on-line interface in an elegant and compact way into the already existing ampoule cracker interface for measuring small samples and are able to switch easily between the 2 gas inputs. The external trap is the central part of the on-line system, as the sample $\mathrm{CO}_{2}$ leaving the EA has to be enriched. Our design is very compact and uses aluminium silicate zeolite (X13, $62 \mathrm{mg}$ ) as the adsorber material, instead of a cryogenic trap that caused breakthroughs of $4-10 \%$ in our experiments. The presented data show that adsorption of even very small samples of $\mathrm{CO}_{2}$ from the EA gas stream is possible with high recoveries close to $100 \%$. However, the application is limited by an additional blank being introduced by the capsule in which the sample material is combusted. We determined this contamination to be $0.34 \pm 0.13 \mu \mathrm{g} \mathrm{C}$ with a relatively stable ${ }^{14} \mathrm{C}$ level of about $65 \mathrm{pMC}$. The influence of this contamination increases as the mass of the sample decreases, according to the model of constant contamination. Although we were able to measure samples down to $3 \mu \mathrm{g} \mathrm{C}$ with the on-line system, it does not make sense to handle samples with carbon contents lower than $10 \mu \mathrm{g}$ as the contribution from the capsule contamination becomes too high. However, a blank value of $1 \mathrm{pMC}(\sim 36 \mathrm{ka})$ is promising. Finally, we demonstrated the reliability of our system by measuring a number of certified standards and previously analyzed samples of different types of material containing 10-30 $\mu \mathrm{g}$ of carbon. The system is fully automated and controlled by LabVIEW software (http://www.ni.com/labview/).

\section{ACKNOWLEDGMENTS}

We are grateful to Marc Mallepell and Max Döbeli (both ETH Zurich) for performing the ERDA measurement and to Matthias Saurer from the Paul Scherrer Institute for discussions and comparison measurements of the elemental analyzer vessels. Stefan Riedi and Reto Kurmann (ETH Zurich) contributed to experiments with different external traps and helped performing the first on-line measurements. We also thank Mojmír Němec for improving the elemental analyzer data and John Southon for his helpful feedback on the manuscript. We also thank Lutz Lange and his team from ELEMENTAR for supporting the work with the EA and satisfying all our special requests. Finally, we thank Rene Gruber, Peter Kägi, and Jürg Thut for their technical support in constructing the gas interface. 


\section{REFERENCES}

Bauer JE, Williams PM, Druffel ERM. 1992. Recovery of submilligram quantities of carbon dioxide from gas streams by molecular sieve for subsequent determination of isotopic $\left({ }^{13} \mathrm{C}\right.$ and $\left.{ }^{14} \mathrm{C}\right)$ natural abundances. $A n$ alytical Chemistry 64:824-7.

Bronk Ramsey C, Hedges REM. 1995. Radiocarbon with gas chromatography. Radiocarbon 37(2):711-6.

Bronk Ramsey C, Ditchfield P, Humm M. 2004. Using a gas ion source for radiocarbon AMS and GC-AMS. Radiocarbon 46(1):25-32.

Kottler C, Dobeli M, Glaus F, Suter M. 2006. A spectrometer for low energy heavy ion ERDA. Nuclear Instruments and Methods in Physics Research B 248(1): 155-62.

Ruff M, Wacker L, Gäggeler HW, Suter M, Synal H-A, Szidat S. 2007. A gas ion source for radiocarbon measurements at $200 \mathrm{kV}$. Radiocarbon 49(2):307-14.

Ruff M, Szidat S, Gäggeler HW, Suter M, Synal H-A, Wacker L. 2010. Gaseous radiocarbon measurements of small samples. Nuclear Instruments and Methods in
Physics Research B 268(7-8):790-4.

Skipper PL, Hughey BJ, Liberman RG, Choi MH, Wishnok JS, Klinkowstein RE, Shefer RE, Tannenbaum SR. 2004. Bringing AMS into the bioanalytical chemistry lab. Nuclear Instruments and Methods in Physics Research B 223-224:740-4.

Synal H-A, Stocker M, Suter M. 2007. MICADAS: a new compact radiocarbon AMS system. Nuclear Instruments and Methods in Physics Research B 259(1): $7-13$

Szidat S, Jenk TM, Gäggeler HW, Synal H-A, Hajdas I, Bonani G, Saurer M. 2004. THEODORE, a two-step heating system for the $\mathrm{EC} / \mathrm{OC}$ determination of radiocarbon $\left({ }^{14} \mathrm{C}\right)$ in the environment. Nuclear Instruments and Methods in Physics Research B 223-224:829-36.

Uhl T, Kretschmer W, Luppold W, Scharf A. 2004. Direct coupling of an elemental analyzer and a hybrid ion source for AMS measurements. Radiocarbon 46(1): 65-75. 